\title{
Cerebral responses to pain in patients with atypical facial pain measured by positron emission tomography
}

\author{
S W G Derbyshire, A K P Jones, P Devani, K J Friston, C Feinmann, M Harris, S Pearce, \\ J D G Watson, R S J Frackowiak
}

\begin{abstract}
The localised PET cerebral correlates of the painful experience in the normal human brain have previously been demonstrated. This study examined whether these responses are different in patients with chronic atypical facial pain. The regional cerebral responses to nonpainful and painful thermal stimuli in six female patients with atypical facial pain and six matched female controls were studied by taking serial measurements of regional blood flow by PET. Both groups displayed highly significant differences in responses to painful heat compared with non-painful heat in the thalamus, anterior cingulate cortex (area 24), lentiform nucleus, insula, and prefrontal cortex. These structures are closely related to the "medial pain system". The atypical facial pain group had increased blood flow in the anterior cingulate cortex and decreased blood flow in the prefrontal cortex. These findings show the importance of the anterior cingulate cortex and the reciprocal (possibly inhibitory) connections with the prefrontal cortex in the processing of pain in patients with this disorder. A hypothesis is proposed to explain the mechanisms of cognitive and pharmacological manipulation of these pain processes.
\end{abstract}

Hammersmith

Hospital, London, UK

$S$ W G Derbyshire

A K P Jones

K J Friston

J D G Watson

R S J Frackowiak

Eastman Dental

Hospital, London, UK

$P$ Devani

C Feinmann

M Harris

Psychology

Department, University College London, UK $S$ Pearce

Correspondence to: Dr Stuart Derbyshire, MRC Cyclotron Unit, Hammersmith Hospital, London W12 0HS, UK

Received 19 July 1993 and in final revised form 16 February 1994. Accepted for publication 28 February 1994 Changes in regional cerebral blood flow (rCBF) can be directly observed by PET and used as an index of neuronal activity. ${ }^{1-3}$ This technique has recently been employed to investigate pain processing in normal volunteers, ${ }^{45}$ and studies have shown activity in areas of the brain associated with painful experience. These include the thalamus, anterior cingulate, and prefrontal cortices. These structures relate to the "media pain system", ${ }^{6-9}$ which is associated with the processing of the emotional components of pain thought to be predominant in chronic rather than acute pain. Acute pain has been associated with the "lateral pain system", which relates to the somatosensory cortex. ${ }^{10}$ The involvement of "medial structures" in the processing of acute pain challenges this classical distinction and indicates the importance of emotional components to the processing of acute pain.

This is not surprising in that pain is now accepted as an experience involving sensory, cognitive-evaluative, and affective motivational components. ${ }^{11}$ This view is complemented by the proposal that the sensory and affective components of pain are processed in parallel, ${ }^{12-14}$ rather than sequentially as had been previously assumed, ${ }^{15}$ and is also supported by evidence that the affective component of pain can be differentially suppressed with morphine, ${ }^{16}$ cingulectomy, ${ }^{17}$ or cognitive intervention. ${ }^{18}$ It is interesting in this context that morphine analgesia is associated with increased blood flow in the prefrontal and anterior cingulate cortex ${ }^{19}$ as well as in the insula and temporal cortex. On the basis of these studies we predicted that the relation between anterior cingulate activity and prefrontal activity would be altered in patients with an idiopathic facial pain presumed to have a major affective component.

Around $40 \%$ of the general population report frequent facial pain and headache, ${ }^{20}$ and many patients referred for specialist consultation are found to have a pain with a strong affective component and a psychiatric basis. Other specialties have similar patients; in one study, $63 \%$ of women presenting with a pelvic disorder were considered to have no demonstrable physical disorder. ${ }^{21}$ Because it is difficult to identify these patients, they are usually subjected to excessive non-invasive and invasive investigation.

We have extended the findings of Jones 


\section{Method}

SUBJECTS

Six female patients with atypical facial pain (age range 42-65 (mean 53) years) and six healthy age matched female controls (age range 47-69 (mean 54.2) years) took part in the study. All 12 subjects were right handed and postmenopausal.

The six patients had had left sided atypical facial pain from one to 16 (mean seven) years, and all had other associated symptoms such as headache, neck ache, pelvic pain, irritable bowel, and pruritus. These patients were chosen because of the refractory nature of their pain in response to antidepressant medication. All such medication was stopped three weeks before the scans. Their neurological, radiological (orthopantomogram and CT), and dental examination findings were normal. The patients were diagnosed as having atypical facial pain on the basis of history, consistent absence of neurological and radiological signs, and negative CT. ${ }^{23}$

Permission to carry out these studies was obtained from the Administration of Radioactive Substances Advisory Committee, UK (ARSAC-UK) and the research ethics committee of Hammersmith Hospital. Fully informed signed consent was obtained from patients before each procedure.

\section{DESIGN}

The patients with atypical facial pain and controls were compared in their response to a series of painful and non-painful intermittent heat stimuli applied to the back of the right hand. Thus two independent variables were explored-namely, painful $v$ non-painful heat in patients with chronic pain $v$ non-pain controls. A non-painful heat was deliberately chosen as a baseline to control for the temporal and somatotopic localisation components of the painful stimulus. A range of dependent variables was also investigated; pain quality as measured by the McGill pain questionnaire, pain intensity as measured by a visual analogue scale, and the regional cortical responses as measured by PET. In these studies changes in blood flow were used as a measure of change in synaptic activity. ${ }^{24}$

\section{APPARATUS}

The stimulus for both hot and painful hot conditions was produced by a Marstock thermal threshold stimulator (Somedic: thermotest Type 1), ${ }^{25}$ which delivers reproducible intermittent ramps of increasing heat to the skin via a water cooled probe.

The visual analogue scales and the McGill scale were displayed by the Macintosh "Hypercard" system in between rCBF measurements.

Scans were obtained with a PET scanner; CTI model 931-08/12 Knoxville, USA (its physical characteristics have been described elsewhere ${ }^{26}$ ).

PROCEDURE

Patients with atypical facial pain were recruited from the facial pain clinic of the
Eastman Dental Hospital. Volunteers were recruited from hospital secretarial staff. All subjects were given a thorough explanation of the procedure.

Before scanning, anxiety and depression were assessed with the Spielberger state/trait self evaluation questionnaire ${ }^{27}$ and Beck depression inventory. ${ }^{28}$ All subjects were then familiarised with the pain visual analogue scale and the McGill pain questionnaire. ${ }^{29}$ They then rated their chronic pain on the visual analogue scale and the McGill pain questionnaire during the scan.

Temperatures that, when applied to the back of the right hand, were reproducibly experienced as non-painful heat or painful heat were established for each subject using the thermal stimulator before the scans.

Each subject was positioned in the scanner so that its axis was roughly parallel to the glabellar-inion line, which in turn is parallel with the line between the anterior and posterior commissures (AC-PC line). A transmission scan was performed with an external ring source of positrons to provide an image of regional tissue density for the correction of emission scans for tissue attenuation effects.

Each subject underwent six sequential scans over the course of a single two hour session, each scan providing measurements of relative regional cerebral blood flow ( $\mathrm{rCBF}$ ). In each subject rCBF was measured by recording the distribution of cerebral radioactivity after inhalation of the freely diffusible positron emitting ${ }^{15} \mathrm{O}$-labelled tracer, carbon dioxide $\left(\mathrm{C}^{15} \mathrm{O}_{2}\right)$. Any increase in $\mathrm{rCBF}$ entails an increase in the amount of radioactivity recorded from that region. ${ }^{30} 31$

Each thermal stimulus was commenced five seconds before the start of the scan Subjects were warned before the start of each stimulation but were not told whether the painful or non-painful temperature was to be applied. The two stimuli were alternated from scan to scan. To avoid any possible order effects, the series commenced with non-painful heat in half the subjects and painful heat in the other half. Each scan lasted two minutes, during which time an intermittent and precisely reproducible ramp of increasing heat was applied to the back of the right hand every 15 seconds. During the time of stimulation the lights were dimmed and silence maintained in order not to contaminate the sensory input. Movement and verbalisation of the subjects during the scans were monitored by observation. After each measurement verbal confirmation was obtained that subjects had experienced the stimulus appropriately as non-painful heat or painful heat. After each scan pain scores were obtained as described. Where applicable, McGill responses and visual analogue scale scores for both the retrospective acute pain and chronic pain were recorded.

Scans were reconstructed with a Hanning filter with a cut off frequency of 0.5 cycles per volume element (pixel), giving a transaxial resolution of $8.5 \mathrm{~mm}$ full width at half 
maximum. This implies that two structures must be at least $8.5 \mathrm{~mm}$ apart to appear as distinct structures. The reconstructed images contained $128 \times 128$ volume elements (pixels), each $2.05 \times 2.05 \times 6.75 \mathrm{~mm}$. The 15 original scan slices were interpolated to produce 43 planes to make these volume elements roughly cubic.

\section{PET DATA ANALYSIS}

The object of the analysis of these studies was to compare changes in blood flow between the different stimulation conditions so that the effect of increasing heat intensity without pain could be contrasted with the effect of painful thermal stimulation. Additionally we compared changes in cerebral blood flow between the two groups so that the effect of pain on patients with chronic pain could be compared with the effect of pain on normal volunteers. To make these comparisons the following procedures were carried out. Head movement between scans was corrected for by aligning all scans with the first one, using automated image registration software specifically developed for the purpose. ${ }^{32}$ Each realigned set of scans from every patient was reorientated into a standardised stereotactic anatomical space. A correction was made for global changes in blood flow between scans. These two procedures allow flow values for each stimulus condition to be pooled across subjects. Finally a statistical comparison of blood flow distributions between conditions and groups was performed to identify sites of significantly changed regional flow. ${ }^{33}$

The AC-PC line was identified directly from the PET image and the data transformed into standard stereotactic space of the stereotactic atlas of Talairach and Tournoux. ${ }^{34}$ To increase the signal to noise ratio and accommodate variability in functional anatomy, each image was smoothed in $\mathrm{X}, \mathrm{Y}$, and $\mathrm{Z}$ dimensions with a Gaussian filter of $20 \mathrm{~mm}$ (full width at half maximum). Differences in global activity were removed after a pixel by pixel analysis of covariance. ${ }^{35}$

The differences between one condition and another were assessed with the appropriate contrast (weighting of the six condition means) by the $t$ statistic. ${ }^{33}$ This analysis was performed for each pixel and the resulting set of $t$ values constituted a statistical parametric $\operatorname{map}(\mathbf{S P M}\{\mathbf{t}\})$.

Table 1 Within group comparison for the control group

\begin{tabular}{|c|c|c|c|c|c|}
\hline \multirow[b]{2}{*}{ Region } & \multirow[b]{2}{*}{ Side } & \multicolumn{3}{|c|}{ Coordinates $(\mathrm{mm})$} & \multirow[b]{2}{*}{ Associated $Z$ value } \\
\hline & & $X$ & $Y$ & $Z$ & \\
\hline $\begin{array}{l}\text { Control group: rCBF increases: } \\
\text { Periaqueductal grey } \\
\text { Lentiform nucleus } \\
\text { Anterior cingulate (area 24) } \\
\text { Frontal pole (area 10) } \\
\text { Medial frontal (area 32) } \\
\text { Inferior parietal (area 40) }\end{array}$ & $\begin{array}{l}\mathbf{M} \\
\mathbf{L} \\
\mathbf{L} \\
\mathbf{R} \\
\mathbf{R} \\
\mathbf{R}\end{array}$ & $\begin{array}{r}2 \\
-26 \\
-12 \\
26 \\
18 \\
54\end{array}$ & $\begin{array}{r}-44 \\
-12 \\
2 \\
42 \\
38 \\
-42\end{array}$ & $\begin{array}{r}-16 \\
8 \\
40 \\
8 \\
24 \\
28\end{array}$ & $\begin{array}{l}3 \cdot 102 \\
3 \cdot 282 \\
3 \cdot 152 \\
4 \cdot 069 \\
5 \cdot 493 \\
3 \cdot 939\end{array}$ \\
\hline $\begin{array}{l}\text { Control group: rCBF decreases: } \\
\text { Prestriate (areas } 18 \text { and 19) } \\
\text { Premotor (area 6) }\end{array}$ & $\begin{array}{l}\mathrm{L} \\
\mathrm{L}\end{array}$ & $\begin{array}{l}-20 \\
-42\end{array}$ & $\begin{array}{r}-56 \\
6\end{array}$ & $\begin{array}{r}4 \\
48\end{array}$ & $\begin{array}{l}4 \cdot 016 \\
3 \cdot 282\end{array}$ \\
\hline
\end{tabular}

All $\mathrm{Z}$ values shown are significant at $\mathrm{p}<0.001$. The $\mathrm{X}, \mathrm{Y}$, and $\mathrm{Z}$ coordinates refer to the atlas of Talairach and Tournoux ${ }^{34}$; see text for details. $M=$ Midline; $L=$ left; $R=$ right
The significance of each $\operatorname{SPM}\{t\}$ was assessed by comparing the observed and expected pixels above a specific criterion $(p<0.001)$. The threshold of $p<0.001$ was chosen because empirical studies with phantoms have shown that this threshold protects against false positives. ${ }^{36}$ Because the significance relates to the profile of $\mathrm{rCBF}$ changes individual foci are reported for descriptive purposes only.

Two planned statistical comparisons were performed; (a) to assess the effects of pain within both groups; and $(b)$ to assess any differences in neurophysiological correlations of pain and heat between the two groups.

Effects of induced pain within each group

The non-painful heat conditions (increasing heat, anticipation of pain) were compared with the painful heat conditions (increasing heat, anticipation of pain, pain). The resulting SPM $\{t\}$ highlighted brain regions in which changes of synaptic activity were associated with pain.

Effects of induced pain between groups

This was assessed by contrasting the changes associated with pain between the groups using the appropriate contrast to define the $t$ statistic. The test for a significant difference in the rCBF responses due to painful heat stimulation in the two groups (normal subjects and patients with atypical facial pain) used the average error variance for the two groups for each pixel.

One tailed tests of significance were made looking for $(a)$ increases in $\mathrm{rCBF}$ associated with induced thermal pain in each group separately, and (b) increases in the pain induced rCBF response in patients with atypical facial pain over and above the increases seen in the volunteers.

\section{Results}

COMPARISON OF NON-PAINFUL AND PAINFUL CORTICAL ACTIVITY DISTRIBUTIONS

Control group

Table 1 shows the areas of significant change of $\mathrm{rCBF}$ on comparing heat with pain in normal volunteers. Increased $\mathrm{rCBF}$ in the region of the periaqueductal grey was found in the midline, increases in the lentiform nucleus were found contralateral to the side of stimulation, and increases in the prefrontal cortex (areas 10, 32) and inferior parietal cortex (area 40) were seen ipsilaterally. The laterality of the increased $\mathrm{rCBF}$ in the anterior cingulate cortex (area 24) cannot be determined within the resolution. Figure 1 shows the increases in blood flow in response to pain for this group. These focal $\mathrm{rCBF}$ increases are in the form of SPM $\{t\}$.

Significant decreases in rCBF were seen in the contralateral prestriate (areas 18, 19) and premotor cortex (area 6). There was no evidence of change in $\mathrm{rCBF}$ in the primary somatosensory cortex on either side. 
Figure 1 Data averaged from the group of six female controls. At the top are transverse images of the brain after stereotaxic normalisation, with the distances from the $A C-P C$ plane indicated.

(A) Averaged blood flow scans. Anatomical landmarks are clearly identified due to differences in flow between grey and white matter.

(B) The arithmetical difference between adjusted mean blood flows for painful hot and non-painful hot phasic stimuli. (C) $S P M\{t\}$ values derived from the formal pixel by pixel comparison of the adjusted mean blood flows and variances for each of the two conditions. The colour scale is arbitrary; threshold significance is indicated by the lower left pixel for each plane. (D) Orthogonal projections of the statistical comparison at $p<0.001$ ( $Z$ threshold 3.09). The areas showing significant increases in blood flow are within the regions of periaqueductal grey, lentiform nucleus, insula, frontal areas 32 and 10 , parietal area 40 , and anterior cingulate cortex. $A C-P C=$ anterior commissure-posterior commissure; $S P M\{t\}=$ statistical parametric map.

in $\mathrm{rCBF}$ on comparing heat with pain in patients with atypical facial pain. The main areas of increased rCBF were contralateral in the lentiform nucleus, insula, and thalamus. The laterality of the increased $\mathrm{rCBF}$ in the anterior cingulate cortex (area 24) was again indeterminate. Figure 2 shows the increases in blood flow in response to pain for this group. These focal $\mathrm{rCBF}$ increases are in the form of SPM $\{t\}$.

Significant decreases in rCBF were seen bilaterally in the prestriate cortex, contralateral premotor (area 6), parietal, and frontal cortices (area 8), and ipsilateral prefrontal cortex (area 10): There was no evidence of significant change in $\mathrm{rCBF}$ in the primary somatosensory cortex on either side.

Table 2 Within group comparison for the atypical facial pain group

\begin{tabular}{|c|c|c|c|c|c|}
\hline \multirow[b]{2}{*}{ Region } & \multirow[b]{2}{*}{ Side } & \multicolumn{4}{|c|}{ Coordinates $(\mathrm{mm})$} \\
\hline & & $X$ & $Y$ & $Z$ & Associated $Z$ value \\
\hline \multicolumn{6}{|c|}{ Patients with atypical facial pain: $\mathrm{rCBF}$ increases: } \\
\hline Periaqueductal grey & M & -2 & -44 & -16 & $3 \cdot 980$ \\
\hline Anterior cingulate (area 24) & $\mathbf{M}$ & 0 & -16 & 36 & 3.417 \\
\hline Lentiform nucleus & L & -16 & -10 & 0 & $3 \cdot 243$ \\
\hline Insula & $\mathrm{L}$ & -38 & 2 & 0 & $3 \cdot 386$ \\
\hline Thalamus & L & -18 & -18 & 12 & $3 \cdot 406$ \\
\hline \multirow{2}{*}{\multicolumn{6}{|c|}{ Patients with atypical facial pain: $\mathrm{rCBF}$ decreases: }} \\
\hline & & & & & $4 \cdot 084$ \\
\hline Area 31 & L & -10 & -58 & 24 & 3.356 \\
\hline Prestriate & L & -34 & -78 & 32 & $3 \cdot 275$ \\
\hline Area 8 & $\mathrm{~L}$ & -28 & 10 & 44 & $4 \cdot 847$ \\
\hline Premotor (area 6) & L & -38 & 6 & 52 & $3 \cdot 273$ \\
\hline Frontal pole (area 10) & $\mathbf{R}$ & 6 & 46 & -8 & 3.982 \\
\hline Medial frontal (area 32) & $\mathbf{R}$ & 4 & 46 & -4 & $3 \cdot 171$ \\
\hline Prestriate (areas 18 and 19) & $\mathbf{R}$ & 12 & -88 & 24 & 3.475 \\
\hline Area 7 & $\mathbf{R}$ & 10 & -74 & 40 & $3 \cdot 222$ \\
\hline
\end{tabular}

$\mathrm{M}=$ Midline; $\mathrm{L}=$ left; $\mathrm{R}=$ right.
COMPARISON OF TCBF INCREASES IN THE CONTROL GROUP WITH INCREASES IN THE ATYPICAL FACIAL PAIN GROUP

Figure 3 shows the comparison of the acute pain changes between the two groups in terms of significant focal differences in the form of SPMs at the appropriate levels in the brain. Activation in the atypical facial pain group was greater in the anterior cingulate cortex (area 24) and significantly less in the ipsilateral prefrontal cortex (area 10).

\section{MEASURES OF DEPRESSION AND PAIN} EXPERIENCE

Table 3 shows that the patients with atypical facial pain scored higher on all the tests of depression and anxiety. These scores were only significantly higher $(p=0.05)$, however, on measures of depression and trait anxiety; not state anxiety (Student's $t$ test).

To determine a measure of sensory intensity, all descriptors selected within the sensory categories of the McGill pain questionnaire were summated by rank value and then divided by the highest possible score. This scoring method yielded values ranging from 0 to 1 with a score of 0 indicating that the subject did not select any adjectives from any of the sensory categories and a score of 1 indicating that the patient selected the highest ranked word in each category. This same procedure was used to obtain a quantitative measure of affective descriptors. These values were averaged for the three retrospective acute pain measures in both groups and for the six chronic atypical facial pain measures in the facial pain group. Table 3 gives the results. 
Figure 2 Data averaged from the group of six female patients with atypical facial pain. At the top are transverse images of the brain after stereotaxic normalisation, with the distances from the $A C-P C$ plane indicated. (A) Averaged blood flow scans. Anatomical landmarks are clearly identified due to differences in flow between grey and white matter. (B) The arithmetical difference between adjusted mean blood flows for painful hot and non-painful hot phasic stimuli. (C) SPM $\{t\}$ values derived from the formal pixel by pixel comparison of the adjusted mean blood flows and variances for each of the two conditions. The colour scale is arbitrary; threshold significance is indicated by the lower left pixel for each plane. (D) Orthogonal projections of the statistical comparison at $p<0.001$ (Z threshold 3.09). The areas showing significant increases in blood flow are within the regions of periaqueductal grey, lentiform nucleus, insula thalamus, and anterior cingulate cortex. $A C-P C=$ anterior commissureposterior commissure; $S P M\{t\}=$ statistical parametric map.

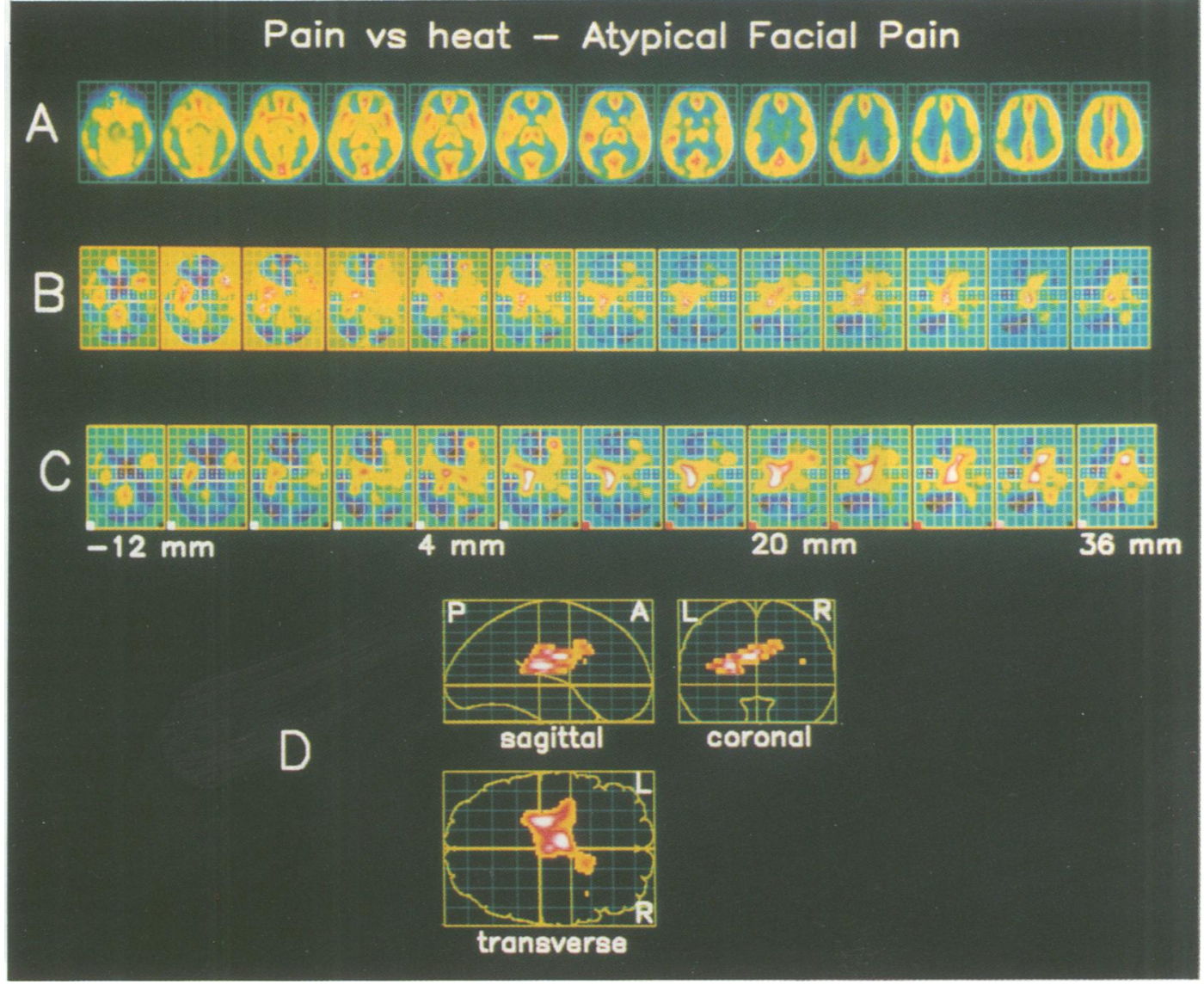

The patients with atypical facial pain gave consistently higher sensory values to their chronic pain but not to induced acute pain, but the differences were not significant.

\section{Discussion}

The experiment was designed to examine the effect of a non-noxious and a noxious stimulus in the presence and absence of a chronic pain with a predominant affective component. The hypothesis under examination was that this pain population will show different cerebral responses to pain in the anterior cingulate and prefrontal cortices compared with a normal population. The tactile components and frequency of stimulation were the same for each non-painful and painful heat stimulation. Thus the comparison of these two stimuli exclude responses to the temporal and spatial components of the stimuli. Anticipation of pain was kept as constant as possible by not informing the patients of the number or order of the different types of stimulation. It is unlikely that the anticipation of pain remained constant throughout the non-painful heat stimulus and it is therefore likely that the

Table 3 Questionnaire results

\begin{tabular}{|c|c|c|}
\hline Questionnaire & Patient score (SD) & Control score (SD) \\
\hline $\begin{array}{l}\text { Beck depression } \\
\text { inventory } \\
\text { State anxiety } \\
\text { Trait anxiety }\end{array}$ & $\begin{array}{l}16.0(10.0) \\
23.2(18 \cdot 67) \\
25.4(17 \cdot 07)\end{array}$ & $\begin{array}{l}4 \cdot 8(5.04)^{\star} \\
12 \cdot 0(8 \cdot 40) \\
15 \cdot 0(6.75)^{\star}\end{array}$ \\
\hline $\begin{array}{l}\text { McGill acute pain: } \\
\text { Sensory scale } \\
\text { Affective scale }\end{array}$ & $\begin{array}{l}0.20(0.12) \\
0.11(0.17)\end{array}$ & $\begin{array}{l}0.25(0.16) \\
0.18(0.21)\end{array}$ \\
\hline $\begin{array}{l}\text { McGill chronic pain: } \\
\text { Sensory scale } \\
\text { Affective scale }\end{array}$ & $\begin{array}{l}0.28(0.06) \\
0.14(0.10)\end{array}$ & 二 \\
\hline
\end{tabular}

"pain response" in this protocol incorporates jects showed any facial or general movement during the scans.

The increases in $\mathrm{rCBF}$ seen in the lentiform nucleus and anterior cingulate were common to both the controls and pain patients and are consistent with our previous findings. ${ }^{4}$ The lack of a thalamic response in the controls is puzzling and not consistent with our previous report, although it is consistent with the findings of Talbot et al. ${ }^{5}$ As the thalamus carries all sensory information to the cortex it is possible that this area shows a smaller relative increase in blood flow with pain compared with heat and is thus more difficult to detect than other areas. This may be investigated in the future with absolute measures of blood flow.

Increases in ipsilateral prefrontal $\mathrm{rCBF}$, seen here in the normal subjects, were also reported previously but at a non-significant level. The prefrontal cortex and anterior cingulate cortex are the main cortical projections of the medial pain system, and have been localised in previous pain studies. ${ }^{45}$ It is therefore suggested that these areas are likely to represent the functional anatomical substrate of pain awareness. Restricting the analysis of the effects of atypical facial pain to these regions, we were able to show that atypical facial pain significantly attenuated the increase in rCBF brought about by induced acute pain in the prefrontal cortex (area 10) while increasing $\mathrm{rCBF}$ in the anterior cingulate cortex (area 24). It is not yet possible to say whether this response is common to all forms of chronic pain or specific to acute pain combined with atypical facial pain. A number some anticipation of pain. None of the sub- 


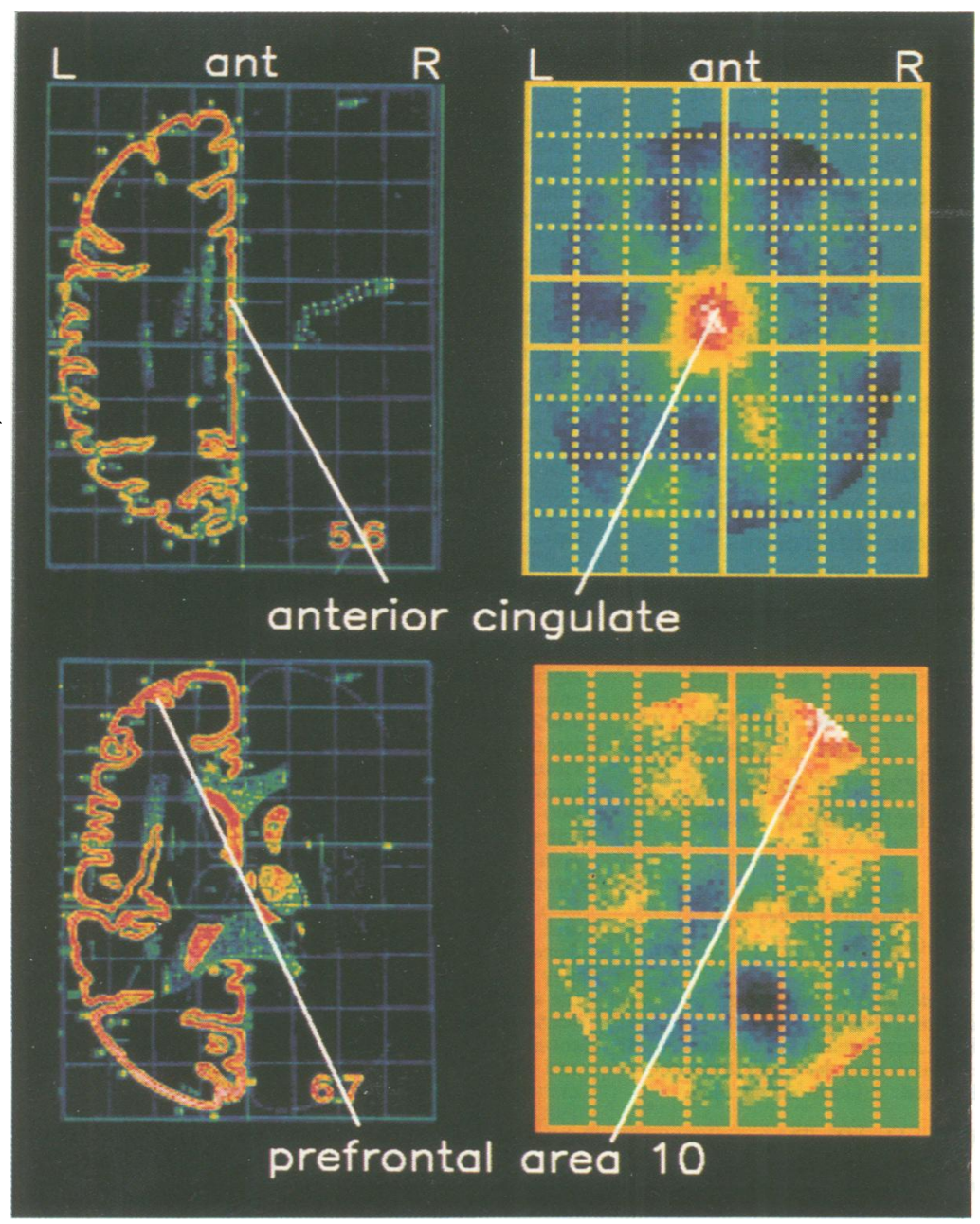

Figure 3 Two statistical parametric maps (SPM $\{t\})$ in the transaxial plane of comparisons described in the main text. The left part of the figure shows the anatomy corresponding to the parametric maps. The top right part of the figure illustrates an $S P M\{t\}$ showing activation of the anterior cingulate in the comparison of the difference between non-painful heat and painful heat between the two groups, with significantly greater activity being found in the group with atypical facial pain. The bottom right part of the figure illustrates an SPM $\{t\}$ showing right sided prefrontal cortex in the comparison of non-painful heat and painful heat differences between the two groups, with greater activity found in the control group. The colour scale is arbitrary and the significance level corresponds to $p=0.001$. The top section is $28 \mathrm{~mm}$ above and parallel to the $A C-P C$ line, the bottom section is $16 \mathrm{~mm}$ above the $A C-P C$ line. $A C-P C=$ anterior commissureposterior commissure; SPM $\{t\}=$ statistical parametric map.

of explanations for this pattern of $\mathrm{rCBF}$ are possible and studies are ongoing with other chronic pain disorders, such as arthritic pain, to discriminate between these possibilities.

Blood flow in the anterior cingulate cortex is thought to reflect the attentional, ${ }^{3}$ motivational, and emotional ${ }^{37}$ aspects of pain processing and response. Studies with rabbits have shown that anterior cingulate lesions interfere with aversive conditioning ${ }^{38}$ and stimulation of area 24 of the anterior cingulate in animals produces a shrill vocalisation response. ${ }^{39}$ Atypical facial pain is often associated with an emotional disturbance ${ }^{22}$ involving some serious life event, such as a bereavement, with inadequate support from relatives or spouse. The anterior cingulate cortex is well placed to integrate variable stressors and to disrupt analgesic mechanisms having reciprocal connections with the medial thalamic nuclei ${ }^{40}$ and projecting to the prefrontal cortex, ${ }^{41}$ striatum, ${ }^{42}$ and periaqueductal grey. ${ }^{43}$ Atypical facial pain, therefore, may be a "hyperemotional" response to incoming sensory information. The finding that chronic pain loses its emotional component after frontal leucotomy and cingulotomy ${ }^{44}$ in combination with the findings reported here lends support to this hypothesis.

The prefrontal cortex has important projections to the anterior cingulate cortex and basal ganglia ${ }^{45}$ as well as weaker connections with the insula cortex. Prefrontal cortical rCBF (area 10) was significantly increased in the control group. Shallice ${ }^{46}$ has proposed that the process by which complex behavioural units or schemas are brought to conscious attention is the function of the "supervisory attention system". This is part of the "programming, regulation, and verification of human activity" 47 by the frontal lobes. Posner and Rothbart $^{48}$ argue that this alert state is lateralised to the right lateral frontal lobe based on its close involvement with the regulations of the heart. The maintenance of vigilance is indexed by a pronounced slowing of the heart. The abnormal pattern of right prefrontal and anterior cingulate responses in these patients may therefore reflect an abnormal "supervision" of attention and emotional schemas. This is consistent with the perception of physical symptoms proposed by Pennebaker. ${ }^{49}$ The common conviction of these patients that there is something structurally wrong with their face,,$^{50}$ and their high trait anxiety, would be seen as a schema in which the likelihood of perceiving painful sensory input from the face is high. ${ }^{51}$

It is apparent from the McGill scores that the chronic and acute pain were not triggering any exceptional emotional response in the patients with atypical facial pain. The affective McGill scores were the same for both groups in response to the acute pain stimulus. This is not consistent with larger group studies ${ }^{50}$ and may relate to a desire by these patients to prove the reality of their atypical facial pain to the medical staff carrying out the scan by denying any emotional input to their disorder. ${ }^{52}$

The pharmacological substrates for the abnormal patterns of pain rCBF seen in the patients with atypical facial pain are not clear. Although about $80 \%$ of cases respond to tricyclic or monoamine oxidase inhibitors only $45 \%$ are found to be depressed..$^{53}$ Furthermore, these patients seem to have a deficit in the excretion of conjugated tyramine comparable to patients with endogenous depression. This biological marker is independent of depression in the patients with atypical facial pain suggesting a neuropharmacological deficit common to both conditions. ${ }^{54}$ It has been suggested that descending cinguloperiaqueductal efferents modulate activity of the descending 5-hydroxytryptamine (5HT) mediated inhibitory system via the middle raphe nuclei in the brain stem. ${ }^{55}$ If uncontrolled this system may deplete serotonin reserves and so disrupt descending analgesia, ${ }^{56}$ or directly interfere with opiate organisation in the cingulate cortex itself. ${ }^{19}$ It is also known that patients with depression have low levels of $5 \mathrm{HT}$ breakdown products in the CSF and that suicide victims have decreased $5 \mathrm{HT}$ and noradrenaline concentrations with increased concentrations of 5HT2 and $\beta$ receptors in the frontal cortex. Increased receptors have 
been suggested as a compensatory mechanism for reduced postsynaptic concentration of these amines. The success of tricyclic antidepressants in patients with atypical facial pain may be explained by the restoration of amine stores. Studies to examine the effects of tricyclic antidepressants on the reversal of rCBF patterns seen in these patients are ongoing and necessary to clarify the possible role of central amine depletion.

In conclusion, important differences between patients with atypical facial pain and normal volunteers have been discovered in the response of the prefrontal cortex and anterior cingulate cortex to pain. These differences in blood flow may be responsible for the maintenance of chronic pain through the failure of inhibition of other cortical and limbic structures. It is likely that this mechanism is related to both overt emotional processing, anxiety, and attentional mechanisms. There is therefore the possibility that, at least for some of these patients, the pain may be brought under conscious control.

This research was supported in part by the Economic and Social Research Council (ESRC grant R00429134074) and in part by the Medical Research Council (MRC).

1 Lueck CJ, Zeki S, Friston KJ, et al. The colour centre in the cerebral cortex of man. Nature 1989;340:386-9.

2 Friston KJ, Frith CD, Liddle PF, Lammertsma AA, Dolan RD, Frackowiak RSJ. The relationship between local and global changes in PET scans. 7 Cereb Blood Flow Metabol 1990;10:458-66.

3 Pardo JV, Pardo PJ, Janer KW, Raichle ME. The anterior cingulate cortex mediates processing selection in the Stroop attentional conflict paradigm. Neurobiology Stroop attention $1990 ; 87: 256-9$.

4 Jones APK, Brown WD, Friston KJ, Qi LY, Frackowiak RSJ. Cortical and subcortical localization of response to pain in man using positron emission tomography. Proc $R$ Soc Lond [Biol] 1991;244:39-44.

5 Talbot JD, Marret S, Evans AC, Meyer E, Bushnell MC, Duncan GH. Multiple representations of pain in human cerebral cortex. Science 1991;251:1355-8.

6 Roland PE. Cortical representation of pain. Trends Neurosci 1992;15:3-5.

7 Stea RA, Apkarian AV. Pain and somatosensory activation. Trends Neurosci 1992;15:250-1.

8 Evans AC, Meyer E, Marret S. Pain and activation in the thalamus. Trends Neurosci 1992;15:252.

9 Roland PE. Reply. Trends Neurosci 1992;15:252-3.

10 Guyton AC. Basic neuroscience: anatomy and physiology. Philadelphia: WB Saunders, 1991.

11 Melzack R, Wall P. The challenge of pain. London: Penguin Books, 1991 .

12 Leventhal H, Everhart D. Emotion, pain, and physical illness. In: CE Izard, ed. Emotions in personality and psychopathology. New York: Plenum Press, 263-99.

13 Leventhal $\mathrm{H}$. A perceptual-motor theory of emotion. Advances in Experimental Social Psychology 1984;17: 117-75

14 Leventhal $\mathrm{H}$, Scherer $\mathrm{K}$. The relationship of emotion to cognition: a functional approach to a semantic controversy. Cognition and Emotion 1987;1:3-28.

15 Beecher HK. Quantification of the subjective pain experience. In: PH Hoch, J Zubin, eds. Psychopathology of perception. New York: Grune and Stratton, 1965:111-28.

16 Kupers R, Konings H, Adriaensen H, Gybels J. Morphine differentially affects the sensory and affective pain ratings in neurogenic and idiopathic forms of pain. Pain ings in neurogen

17 Foltz EL, White LEJ. Pain relief by frontal cingulotomy. Neurosurgery 1962;19:89-100.

18 Leventhal H, Brown D, Shacham S, Engquist G. Effects of preparatory information about sensations, threat of pain, 1979;37:688-714.

19 Jones AKP, Friston KJ, Qi LY, et al. The sites of action of morphine on the human brain studied with positron emission tomography. Lancet 1991;338:825.

20 Agerberg D, Carlson GE. Functional disorders of the masticatory system. Distribution of symptoms according to age and sex as judged by questionnaire. Acta Odontol Scand 1972;30:577-613.

21 Pearce S. The concept of psychogenic pain. A psychophysical investigation of women with pelvic pain. In: $M$ Johnson, T Marteu, eds. Applications in health psychology. New Jersey: Transaction, 1989.

22 Feinmann C, Harris M. Psychogenic facial pain, part 1: the clinical presentation. Br Dent $f$ 1984;156:165-8.

23 Feinmann C, Harris M. Psychogenic facial pain (part 2): management and prognosis. Br Dent $\mathcal{F} 1984 ; 156: 205-8$.
24 Friston KJ, Frackowiak RSJ. Imaging functional anatomy. Alfred Benzon symposium 31. Copenhagen: Munksgaard, 1991

25 Fruhstorfer H, Lindblom U, Schnidt WG. Method for quantitative estimation of thermal thresholds in patients. fournal of Neurology and Psychiatry 1976;39:1071-5.

26 Spinks TJ, Jones T, Gilardi MC, Heather JD. Performance characteristics of a whole body positron tomograph. IEEE Transactions on Nuclear Science 1988;35:721-5.

27 Spielberger CD, Gorsuch RL, Lushene R. Manual for the state-trait anxiety inventory. Palo Alto, CA: Consulting Psychologists' Press, 1970.

28 Beck AJ, Ward CH, Medelson M, Mock J, Erbaugh J. An inventory for measuring depression. Arch Gen Psychiatry 1961;4:561-7

29 Melzack R. The McGill pain questionnaire: major properties and scoring methods. Pain 1975;1:277-99.

30 Mazziotta JC, Huang SC, Phelps ME, Carson RE, Macdonald NS, Mahoney K. A non-invasive positron computed tomography technique using oxygen-15 labeled water for the evaluation of neurobehavioural task batteries. F Cereb Blood Flow Metab 1985;5:70-8.

31 Fox PT, Mintum MA. Noninvasive functional brain mapping by change- distribution analysis of averaged PET
images of $\mathrm{H}_{2}{ }^{15} \mathrm{O}$ tissue activity. $\Im \mathrm{Nucl}$ Med 1989;30: 141-9.

32 Woods RP, Cherry SR, Mazziotta JC. A rapid automated algorithm for accurately aligning and reslicing positron emission tomography images. $\mathcal{F}$ Comput Assist Tomogr 1992;16:620-33.

33 Friston KJ, Frith PF, Liddle PF, Frackowiak RSJ Comparing functional (PET) images: the assessment of
significant change. $¥$ Cereb Blood Flow Metab 1991;11: 690-9.

34 Talairach J, Tournoux P. Co-planar stereotaxic atlas of the human brain. Stuttgart: Georg Thieme, 1988.

35 Friston KJ, Frith CD, Liddle PF, Lammertsma AA, Dolan RD, Frackowiak RSJ. The relationship between local and global changes in PET scans. $\mathcal{F}$ Cereb Blood Flow Metab 1990;10:458-66.

36 Bailey DL, Jones T, Spinks TJ. A method for measuring the absolute sensitivity of positron emission tomographic scanners. Eur f Nucl Med 1991;18:374-9.

37 Gabriel M, Orona E, Foster K, Lambert RW. Mechanisms and generality of stimulus significance coding in a mammalian model system. Advances in Behavioural Biology 1982;26:535-67.

38 Gabriel M. Functions of anterior and posterior cingulate cortex during avoidance learning in rabbits. In: HBM cortex during avoidance learning in rabbits. In: HBM MGlings, CG Van Eden, JPC De Bruin, MA Corner, MGP Feenstra, eds. The

39 Vogt BA, Rosene DL, Pandya DN. Thalamic and cortical afferents differentiate anterior from posterior cingulate cortex in the monkey. Science 1979;204:205-7.

40 Domesick V. Projections from the cingulate cortex in the rat. Brain Res 1969;12:296-320.

41 Pandya D, Van Hoesen G, Mesulam MM. Efferent connections of the cingulate gyrus in the rhesus monkey. Exp Brain Res 1981;42:319-30.

42 Royce G. Laminar origin of cortical neurons which project upon the caudate nucleus: a horseradish peroxidase investigation in the cat. $\mathcal{F}$ Comp Neurol 1982;205:8-29.

43 Muller-Preuss P, Jurgens U. Projections from the "cingular" vocalization area in the squirrel monkey. Brain Res 1976;103:29-43.

44 Bouckoms AJ. Psychosurgery. In: Wall PD, Melzack R eds. Textbook of pain: 2nd ed. Edinburgh: Churchill eds. Textbook of pain: 2 .
Livingstone, 1989:666-76.

45 Groenewegen HJ, Berendse HW, Wolters JG, Lohman AHM. The anatomical relationship of the prefrontal cortex with the striatopallidal system, the thalamus and the amygdala: evidence for a parallel organization. In: HBM Uylings, CG Van Eden, JPC De Bruin, MA Corner, MGP Feenstra, eds. The Prefrontal Cortex. Amsterdam: Elsevier, 1990

46 Shallice T. Specific impairements of planning. Phil Trans $R$ Soc Lond B 1982;298:199-209.

47 Luria AR. The working brain. An introduction to neuropsychology. Translated by B Haigh. New York: Basic Books, 1977:187.

48 Posner MI, Rothbart MK. Attentional mechanisms and conscious experience. In: D Milner, $M$ Rugg, eds. The neuropsychology of consciousness. London: Academic Press, 1991.

49 Pennebaker J. The psychology of physical symptoms. New York: Springer-Verlag, 1982.

50 Harris M, Feinmann C. Psychosomatic disorders. In: MK Mason, JG Jones, eds. Oral manifestations of systemic disease. Philadelphia: WB Saunders, 1990.

51 Eysenck MW, Macleod C, Mathews A. Cognitive functioning and anxiety. Psychol Res 1987;49:189-95.

52 Pilowsky I, Bassett D, Barret R, Petrovic L, Minniti R The illness behaviour assessment schedule: reliability and validity. Int $\mathcal{F}$ Psychiatry Med 1983-4;131:1 1-28.

53 Feinmann C. Pain relief by antidepressants: possible modes of action. Pain 1985;23:1-8.

54 Ashabeigi B, Feinmann C, Glover V, Goodwin B, Hannah $P$, Sandler $M$, Wasil $M$. Tyramine conjugation deficit in patients with chronic idiopathic temporomandibular joint and orofacial pain. Pain 1993;54:159-63.

55 Sikes RW, Vogt BA. Nociceptive neurons in area 24 of rabbit cingulate cortex. F Neurophysiol 1992;68:1720-32.

56 Melzack R, Stotler WA, Livingstone WK. Effects of discrete brainstem lesions in cats on perception of noxious stimulation. $\mathcal{F}$ Neurophysiol 1958;21:353-67. 